\title{
Complete Aortic Prosthetic Valve Dehiscence after Modified Bentall-De Bono Procedure
}

\author{
Onur Tasar, Arzu Kalayci', Can Yucel Karabay², Cevat Kirma' ${ }^{1}$ \\ Department of Cardiology, Elazig Education and Research Hospital, Elazig, 'Department of Cardiology, Kosuyolu Heart Education and Research Hospital, \\ ${ }^{2}$ Department of Cardiology, Dr. Siyami Ersek Education and Research Hospital, Istanbul, Turkey
}

\section{Abstract}

A 56-year-old male patient was admitted to our clinic due to persistent fever despite the use of antibiotics for 2 weeks, chest pain, and presyncope. His medical history revealed that the patient underwent modified Bentall-De Bono procedure 2 months ago due to ascending aortic aneurysm and severe aortic insufficiency. Transthoracic apical 5 chamber view showed that mobile vegetation prolapsed into the left ventricular outflow tract during ventricular diastole and that mechanical prosthetic valve was superior to the aortic annulus. Transesophageal echocardiography revealed normal aortic mechanical prosthetic valve function; however, the valve was positioned more superior to the annular plane and a dense vegetation was observed. Moreover, a complete dehiscence of the prosthetic valve was attached to aortic annulus with a single stitch in an area between noncoronary sinus and left coronary sinus. Dense thrombus formation was observed in the perivalvular region. Many cases with prosthetic valve endocarditis and partial dehiscence as its complication have been reported in the literature. However, to the best of our knowledge, there is no reported case of complete dehiscence secondary to infective endocarditis following complete ascending aortic graft and prosthetic aortic valve replacement (modified Bentall-De Bono procedure).

Keywords: Complete dehiscence, endocarditis, prosthetic valve

\section{INTRODUCTION}

Aortic valve prosthesis dehiscence is an uncommon complication of aortic valve surgery. It is usually recognizable at echocardiography due to an abnormal position of the prosthetic valve in relation to the native aortic annulus in conjunction with an abnormal periaortic space that fills with thrombus. We present a patient with complete aortic prosthetic valve dehiscence and periaortic thrombus.

\section{Case Report}

A 56-year-old male patient was admitted to our clinic due to persistent fever despite the use of antibiotics for 2 weeks, chest pain, and presyncope. His medical history revealed that the patient underwent modified Bentall-De Bono procedure 2 months ago due to ascending aortic aneurysm and severe aortic insufficiency. On physical examination, his general condition was poor, he had tachypnea and tachycardia, his

\begin{tabular}{|l|l|}
\multicolumn{2}{c|}{ Video Available on: http://www.ijcva.com } \\
\hline \multicolumn{3}{|c|}{ Access this article online } \\
\hline Quick Response Code: & $\begin{array}{l}\text { Website: } \\
\text { http://www.ijcva.com }\end{array}$ \\
\cline { 2 - 2 }
\end{tabular}

body temperature was $39.3^{\circ} \mathrm{C}$, and his skin was pale and clammy. His blood pressure was $110 / 45 \mathrm{mmHg}$, and pulse rate was $117 \mathrm{bpm}$; electrocardiography showed sinus rhythm. Laboratory examination revealed a white blood cell count of $26,000 / \mathrm{mm}^{3}$, hemoglobin level of $9.6 \mathrm{~g} / \mathrm{dL}$, and high-sensitivity C-reactive protein level of $119 \mathrm{mg} / \mathrm{dL}$.

Transthoracic apical 5 chamber view showed that mobile vegetation prolapsed into the left ventricular outflow tract during ventricular diastole and that mechanical prosthetic valve was superior to the aortic annulus [Figure Panel 1a and Supplementary Video 1]. Transesophageal echocardiography revealed normal aortic mechanical prosthetic valve function; however, the valve was positioned more superior to the annular plane and a dense vegetation was observed [Figure Panel $1 \mathrm{~b}$ and c, Supplementary Video 1]. Moreover, a complete

Address for correspondence: Dr. Onur Tasar, Inonu Cad. No: 74, 23200 Elazig, Turkey. E-mail: tasaronur@hotmail.com

This is an open access journal, and articles are distributed under the terms of the Creative Commons Attribution-NonCommercial-ShareAlike 4.0 License, which allows others to remix, tweak, and build upon the work non-commercially, as long as appropriate credit is given and the new creations are licensed under the identical terms.

For reprints contact: reprints@medknow.com

How to cite this article: Tasar O, Kalayci A, Karabay CY, Kirma C. Complete aortic prosthetic valve dehiscence after modified Bentall-De Bono procedure. Int J Cardiovasc Acad 2018;4:10-1. 

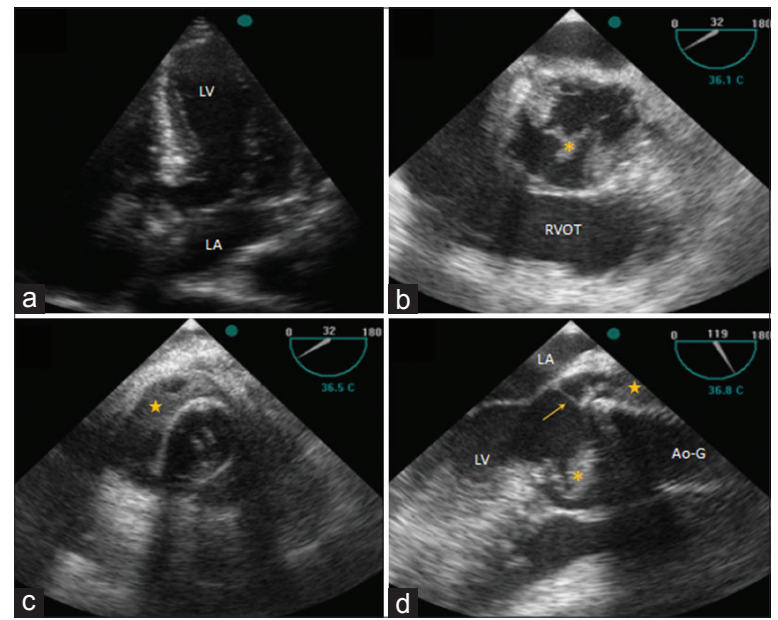

Figure 1: (a) Prosthetic valve was superior to the annular plane. (b) Vegetation at the aortic annulus (asterisks) and displacement of the prosthetic valve. (c) The prosthetic valve and dense thrombus formation (star) around it. (d) Vegetation (asterisk), complete dehiscence of the prosthetic valve attached to aortic annulus with a single stitch in between noncoronary sinus and left coronary sinus (arrow), and thrombus around aortic graft (star). LA: Left atrium, LV: Left ventricle, RA: Right atrium, RV: Right ventricle RVOT: Right ventricle outflow tract, Ao-G: Aortic graft, P-AV: Prosthetic aortic valve

dehiscence of the prosthetic valve was attached to aortic annulus with a single stitch in an area between noncoronary sinus and left coronary sinus [Figure Panel 1d and Supplementary Video 1]. Dense thrombus formation was observed in the perivalvular region. The patient underwent emergency operation due to complete dehiscence. Intraoperative macroscopic findings were consistent with the echocardiographic findings.

\section{ConcLusion}

Infective endocarditis is a severe clinical problem, with considerable morbidity and mortality, characterized by microbial infection of intracardiac endothelial lining commonly involving one or more cardiac valves and less frequently mural endocardium, chordae, and myocardium. Intracardiac or endovascular devices or graft materials act as a reservoir for infection and also complicate the treatment. ${ }^{[1,2]}$ Prosthetic valve endocarditis differs from native valve endocarditis in terms of prevalence, microbial agents, complications, and management. Today, significant portion of patients with infective endocarditis have prosthetic valve endocarditis. In prosthetic valve endocarditis, unlike native valve endocarditis, annular abscess, fistulization, severe valvular dysfunction, and dehiscence are the main severe complications; the presence of dehiscence being the case in our patient. ${ }^{[1,3,4]}$ Many cases with prosthetic valve endocarditis and partial dehiscence as its complication have been reported in the literature. However, to the best of our knowledge, there is no reported case of complete dehiscence secondary to infective endocarditis following complete ascending aortic graft and prosthetic aortic valve replacement (modified Bentall-De Bono procedure). Our purpose in the present paper is to discuss an undesired early complication following complete ascending aorta and prosthetic valve replacement with demonstrative images.

\section{Declaration of patient consent}

The authors certify that they have obtained all appropriate patient consent forms. In the form the patient(s) has/have given his/her/their consent for his/her/their images and other clinical information to be reported in the journal. The patients understand that their names and initials will not be published and due efforts will be made to conceal their identity, but anonymity cannot be guaranteed.

\section{Financial support and sponsorship}

Nil.

\section{Conflicts of interest}

There are no conflicts of interest.

\section{RefEREnCES}

1. Ivert TS, Dismukes WE, Cobbs CG, Blackstone EH, Kirklin JW, Bergdahl LA, et al. Prosthetic valve endocarditis. Circulation 1984;69:223-32.

2. Piper C, Körfer R, Horstkotte D. Prosthetic valve endocarditis. Heart 2001;85:590-3.

3. Ling LF, To AC, Menon V. Staphylococcus aureus endocarditis complicated by aortic root abscess, coronary fistula, and mitral valve perforation. J Am Coll Cardiol 2012;59:e31.

4. Güler A, Aung SM, Karagöz A, Kırma C. Intracardiac fistula in a patient with prosthetic valve endocarditis. Turk Kardiyol Dern Ars 2012;40:107. 